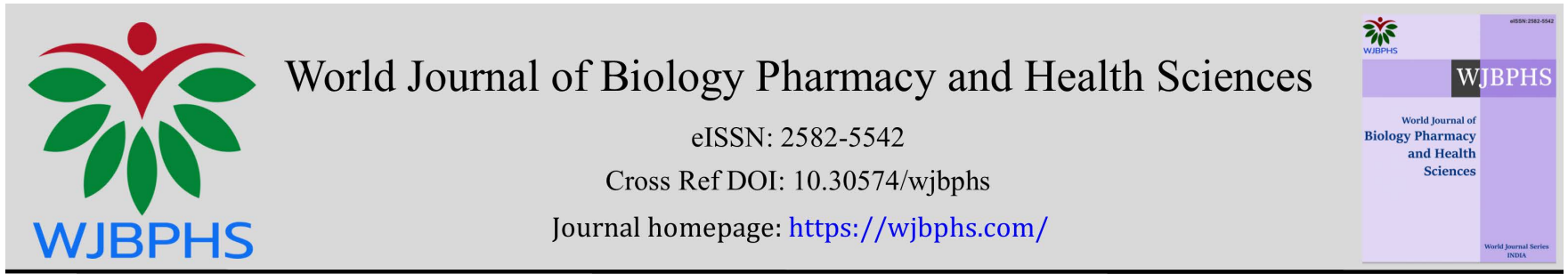

(RESEARCH ARTICLE)

\title{
Investigation the effects of varicocelectomy on sex hormones levels and semen parameters
}

Fatemeh Soheili * and Mohamad Falahati

Department of Biology, Karaj Branch, Islamic Azad University, Karaj, Iran.

World Journal of Biology Pharmacy and Health Sciences, 2021, 06(02), 007-013

Publication history: Received on 27 March 2021; revised on 30 April 2021; accepted on 03 May 2021

Article DOI: https://doi.org/10.30574/wjbphs.2021.6.2.0040

\begin{abstract}
Background: Varicocelectomy is a type of surgery for varicocele treatment. This may recover fertility properties in males through improvement in semen parameters as well as sexual hormones. In this study, the role of varicocelectomy with focus on semen properties and sexual hormones have been assessed.
\end{abstract}

Methods: In this cross-sectional study, before- after data from fifteen patients with different varicocele grade, regarding to varicocelectomy have been compared.

Result: After varicocelectomy, a significant improvement in some semen parameters such as motility and concentration has been showed. However, among sexual hormones, only testosterone has been increased after surgical intervention $(\mathrm{p}=0.007)$.

Conclusion: Based on our knowledge, varicocele treatment may almost improve fertility potential in males significantly. Accordingly, it seems that varicocelectomy has positive effect on parameters such as testosterone and serum FSH levels as well as sperm count and motility. Therefore, it could be concluded that varicocelectomy is an effective approach to improve male fertility and sexual disorders.

Keywords: Varicocele; Varicocelectomy; Sexual hormones; Semen.

\section{Introduction}

Male infertility is a widespread problem in men. Several factors have been identified for male infertility in which the most important is varicocele. It can be considered as important factors along with early testicular disorders and obstruction in the genital tract(1). Varicocele is a complication that is caused by anomalies of the veins inside the testicles, resulting in a backup of blood that cannot flow, which in turn causes swelling(2). An overall prevalence of varicocele is $15 \%$ to $45 \%$ in men. Clinical manifestation appears at puberty, with an estimated prevalence of about $1 \%$ before adolescence, about 2 to $16 \%$ in adolescence and about $20 \%$ at age 15(3). It has been reported several factors which include oxidative stress followed by hypoxia and imbalance of hormones. The main mechanism of varicocele is DNA damage in the sperm head due to oxidative stress (with high levels of active oxygen species) or reduction of Total Antioxidant Capacity (TAC)(4). Moreover, the progression of varicocele during adolescence may have deleterious effects on male reproductive system. Increase or decrease in testis size may be related to varicocele(5). Once varicocele occurred, some of its prominent features such as reduced sperm count, as well as decreased testosterone levels, along with diminished size in the same area can be observed(6). It can be associated with a distinct or obscure pain in the testicles or groin area(7). Other symptoms are including heavy testicular sensation, testicular atrophy, benign prostatic hyperplasia, and related urinary problems(8). Causative factors for varicocele are not clearly known and various causes

\footnotetext{
* Corresponding author: Fatemeh Soheili

Department of Biology, Karaj Branch, Islamic Azad University, Karaj, Iran.
} 
such as hyperthermia, testicular blood flow, intravenous pressure, hormonal disorders, renal reflux, autoimmune disorders, and oxidative stress are suggested(9). Hormonal disorders have been reported in varicocele, however, the testosterone hormone varies in different degrees in varicocele(10). Surgical treatment through varicocelectomy can affect serum testosterone levels in affected male. On the other hand, they are at risk of androgen deficiency(11). Some studies have shown that varicocelectomy can significantly correct the sperm parameters, as well as the level of sex hormones such as serum testosterone level(12). Varicocelectomy is a surgical procedure to improve the fertility in men. In fact, the purpose of this surgical procedure is to treat varicocele by preventing intravenous drainage of the reflux into the testicle and continuing with maintaining arterial flow and lymph drainage(13). Evidence also suggests that varicocele modification can improve postoperative testosterone levels, while the role of varicocelectomy as a dysfunctional method on sperm parameters is also considered to be effective (and somewhat accepted) (14). We aimed to investigate the effect of micro-surgical varicocelectomy on sex hormones in affected men.

\section{Material and methods}

Fifteen varicocele patients who referred to the Infertility and Urology Center in Karaj, Iran, for infertility or pain in the genital area were studied. Patients were examined by an urologist. After diagnosis, a complete medical history and hormonal profiles and their demographic information were recorded. After filling out the consent form, a questionnaire for each patient was obtained. Exclusion criteria were as follows: testicular atrophy, genitourinary infection of cryptorchidism, testicular trauma, post-genital tuberculosis patients, hyperprolactinemia, and use of testosterone or antistatic substitutes, aromatase suppressants, uncontrolled diabetes and high blood pressure. Varicocele patients were classified into 1 to 3 grades in terms of severity of varicocele according to the Dubin and Amelar systems (18). The microsurgical varicocelectomy was performed in the present study by the method described by Zini et al. (19), in which Both the internal and external spermic vessels were blocked, while the elliptic and lymphatic arteries were open. Sperm samples were collected by self-stimulation after 3 days of abstinence. Semen analysis was performed for parameters such as concentration, viability, percentage of movement, shape and morphology of sperm based on the WHO criteria. Endocrinologic evaluation for serum testosterone levels, $\mathrm{FSH}$, and $\mathrm{LH}$, was evaluated by electrochemiluminescence evaluation. The data obtained from the semen analysis and the evaluation of pre-operative sexual hormones were compared with these parameters four months after the operation of varicocelectomy. Data were analyzed using SPSS software through paired t test and Wilcoxon tests. P-value less than 0.05 was considered significant.

\section{Results}

\subsection{Demographic Information}

In this study, 15 males with varicocele were conducted and include into the study. The mean age of patients was 29.47 \pm 5.87 . Demographic data showed that $26.7 \%$ of patients had a history of smoking and $23.1 \%$ had a family history with their spouse (Table 1).

Table 1 Demographic information of varicocele patients

\begin{tabular}{|l|l|c|c|}
\hline \multicolumn{2}{|c|}{} & Frequency (n) & Percent \\
\hline \multirow{3}{*}{ Consanguinity } & yes & 3 & $23.1 \%$ \\
\cline { 2 - 4 } & no & 10 & $76.9 \%$ \\
\hline \multirow{3}{*}{ Family history } & yes & 2 & $13.3 \%$ \\
\cline { 2 - 4 } & no & 13 & $86.7 \%$ \\
\hline \multirow{3}{*}{ Smoking } & yes & 4 & $26.7 \%$ \\
\cline { 2 - 4 } & no & 11 & $73.3 \%$ \\
\hline \multirow{3}{*}{ Addiction } & yes & 2 & $13.3 \%$ \\
\cline { 2 - 4 } & no & 13 & $86.7 \%$ \\
\hline \multirow{2}{*}{ Alcohol } & yes & 1 & $6.7 \%$ \\
\cline { 2 - 4 } & no & 14 & $93.3 \%$ \\
\hline
\end{tabular}


The results showed that most of the subjects in the study had varicocele grade II (7.86\%), while only $13.3 \%$ of the subjects had grade III varicocele (Table 2).

Table 2 Frequency and percentage of participants based on varicocele grade

\begin{tabular}{|c|c|c|c|c|}
\hline Varicocele Grade & Frequency & Percent & Valid Percent & Cumulative Percent \\
\hline two & 13 & 86.7 & 86.7 & 86.7 \\
\hline three & 2 & 13.3 & 13.3 & 100.0 \\
\hline Total & 15 & 100.0 & 100.0 & \\
\hline
\end{tabular}

According to the results, the mean FSH before and after intervention was $11.75 \pm 9.83 \mathrm{IU} / \mathrm{L}$ and $10.04 \pm 8.72 \mathrm{IU} / \mathrm{L}$ respectively (table 3), which according to Wilcoxon test, there was no significant difference between these two phases $(\mathrm{P}=0.069)$. Mean LH before and after intervention was $4.25 \pm 6.55 \mathrm{IU} / \mathrm{L}$ and $6.20 \pm 7.07 \mathrm{IU} / \mathrm{L}$ respectively which there was no significant difference between these two phases $(\mathrm{P}=0.820)$. The mean of prolactin before and after intervention was $180.08 \pm 373.70 \mu \mathrm{IU} / \mathrm{ml}$ and $342.43 \pm 284.25 \mu \mathrm{IU} / \mathrm{ml}$ respectively, and the difference before and after the intervention was not significant $(\mathrm{P}=0.670)$.

Table 3 Sexual hormone profile before and after intervention

\begin{tabular}{|l|l|l|l|l|l|l|l|l|}
\hline Sexual hormone & \multicolumn{2}{|c|}{ Before } & \multicolumn{2}{c|}{ After } & \multicolumn{2}{c|}{ Difference } & \multirow{2}{*}{ t-test } & \multirow{2}{*}{ P-value } \\
\cline { 1 - 7 } & Mean & SD & Mean & SD & Mean & SD & & \\
\hline FSH(IU/L) & 9.83 & 11.75 & 8.72 & 10.04 & 1.11 & 3.99 & -1.818 & 0.069 \\
\hline LH(IU/L) & 6.55 & 4.25 & 7.07 & 6.20 & -.52 & 3.71 & -0.227 & 0.820 \\
\hline Prolactin $(\mu \mathrm{IU} / \mathrm{ml})$ & 373.70 & 180.08 & 342.43 & 284.25 & 31.27 & 278.47 & 0.435 & 0.670 \\
\hline Testosterone(ng/ml) & 3.02 & 1.33 & 4.06 & 1.51 & -1.04 & 1.29 & -3.140 & $0.007^{*}$ \\
\hline
\end{tabular}

The results showed that the mean of testosterone was $1.33 \pm 3.02 \mathrm{ng} / \mathrm{ml}$ and $5.0 \pm 1.5 \mathrm{ng} / \mathrm{ml} \mathrm{before} \mathrm{and} \mathrm{after}$ intervention respectively which there was a significant difference between these two measurements $(\mathrm{P}=0.007)$.

The results showed that the mean volume of semen before and after intervention was $2.32 \pm 1.32 \mathrm{ml}$ and $3.15 \pm 1.22 \mathrm{ml}$ respectively, which was not significant $(\mathrm{P}=0.054)$. The value of $\mathrm{pH}$ before and after the intervention was constant and equal to 7.8 and unchanged. According to the results, the mean progressive motility before and after intervention was $33.87 \pm 23.34 \%$ and after intervention $40.95 \pm 21.31 \%$ respectively. There was no significant difference between these two times $(\mathrm{P}=0.136)$. According to the results of this study, the mean of Sperm motility index before intervention was $108.66 \pm 104.56$ and after intervention was $104.40 \pm 72.56$ which was not significant $(\mathrm{P}=0.053)$. The mean total motile sperm before intervention was million. $58.77 \pm 77.13$ while after intervention, was $64.68 \pm 74.68(\mathrm{P}=0.001)$. The results also showed that the mean total functional sperm concentration before and after intervention were $40.09 \pm 50.39$ and $42.06 \pm 51.26$ million respectively (Table 4 ), which was statistically significant $(\mathrm{P}=0.003)$. 
Table 4 Semen parameters before and after intervention

\begin{tabular}{|c|c|c|c|c|c|c|c|c|}
\hline \multirow{2}{*}{ Parameters } & \multicolumn{2}{|c|}{ Before } & \multicolumn{2}{|c|}{ After } & \multicolumn{2}{|c|}{ Difference } & \multirow{2}{*}{ t-test } & \multirow{2}{*}{ P-value } \\
\hline & Mean & SD & Mean & SD & Mean & SD & & \\
\hline Semen volume(ml) & 2.32 & 1.32 & 3.15 & 1.22 & -.83 & 1.53 & -2.108 & 0.054 \\
\hline $\mathrm{P}^{\mathrm{H}}$ & 7.80 & 0.00 & 7.80 & 0.00 & 0.00 & 0.00 & --- & --- \\
\hline Alive total concentration $\left(10^{6} / \mathrm{ml}\right)$ & 39.39 & 43.67 & 33.54 & 29.65 & 5.85 & 43.86 & 0.517 & 0.613 \\
\hline Progressive motility (\%) & 33.87 & 23.34 & 40.95 & 21.31 & -7.08 & 17.32 & -1.583 & 0.136 \\
\hline Normal morphology (\%) & 26.27 & 13.92 & 30.07 & 12.98 & -3.80 & 11.78 & -1.249 & 0.232 \\
\hline $\begin{array}{l}\text { Motile sperm } \\
\text { Concentration }\left(10^{6} / \mathrm{ml}\right)\end{array}$ & 21.93 & 31.01 & 24.00 & 31.49 & -2.07 & 1.48 & -3.409 & $0.001^{*}$ \\
\hline $\begin{array}{l}\text { Functional sperm concentration } \\
\left(10^{6} / \mathrm{ml}\right)\end{array}$ & 18.72 & 24.07 & 20.55 & 25.55 & -1.83 & 1.65 & -3.409 & $0.001^{*}$ \\
\hline Sperm motility index & 108.53 & 104.66 & 104.40 & 72.56 & 4.13 & 57.20 & -1.932 & 0.053 \\
\hline All sperm(million) & 100.97 & 117.05 & 110.38 & 121.93 & -9.41 & 13.47 & -3.410 & $0.001^{*}$ \\
\hline Total motile sperm(million) & 58.77 & 70.13 & 64.68 & 74.08 & -5.91 & 5.55 & -3.295 & $0.001^{*}$ \\
\hline $\begin{array}{lr}\text { Total functional } & \text { sperm } \\
\text { concentration(million) }\end{array}$ & 40.09 & 50.39 & 42.06 & 51.26 & -1.97 & 2.08 & -3.670 & $0.003^{*}$ \\
\hline
\end{tabular}

\section{Discussion}

Varicocele has deleterious effects on spermatogenesis through increase of testicular temperature and the reflux of toxic metabolites (15). Varicocele can be corrected by varicocelectomy as a surgical technique to treatment of infertility in men which is done in both adults and adolescents Moreover, it can be as a treatment for testicular hemorrhage, hypogonadism and the improvement of sex hormones such as testosterone (16). In the present study it has been demonstrated that varicocelectomy may have corrective effects in infertile patients. Our finding showed that testosterone level was $3.02 \mathrm{ng} / \mathrm{ml}$ before surgery, however, after surgery, a significant elevation up to $4.06 \mathrm{ng} / \mathrm{ml}$ have been found $(\mathrm{P}=0.007)$. Several studies showed that men with a total testosterone level below $400 \mathrm{ng} / \mathrm{dl}-1(4 \mathrm{ng} / \mathrm{ml})$ had higher serum testosterone levels than normal total testosterone (17). However, in other studies, there was no significant increase in testosterone levels after varicocelectomy (18). su et.al showed that serum total testosterone levels increased after varicocele surgery. Also, they showed that varicosal clinical grade and improvement in serum level of patients after the operation of varicoclonectomy are not related. In another study, serum testosterone increased after this operation, but this change was not observed in all patients (19). ). In addition, similar results were obtained in other studies $(20,21)$. Resorlu et al. did not see any changes in serum total testosterone levels in infertile patients after surgery, and this was consistent with the study of su et.al. Consequently, the likelihood of abnormalities in the Leydig cells will be corrected by this surgery. They showed that the age variable is not a major contributor to varicocelectomy surgery, and the high rate of success in the surgery has been similar results for different ages (22). Varicocelectomy in older patients with hypogonadism also has more satisfactory results (17). A study by Ishwaika et al. Showed that serum testosterone levels are not sufficient to estimate the production of elliptic androgens. In this study, serum testosterone level was normal in patients with varicocele, but the production of elliptic testosterone has shown decreased in varicocele patients. In this study, increased serum free testosterone levels after varicocelectomy resulted in increased concentrations and sperm motility (23). There is no significant relationship between the mechanisms that shows how varicocele affects the synthesis of testosterone. But the mechanisms that are likely to reduce the activity of 17 and 20 desmolase and 17 a-hydroxylase, the disruption of these enzymes could increase the testicular temperature and disorder the response of leydig cells to defective gonadotrophin stimulation(24). Also, the varicocelectomy and its effect on sperm parameters were evaluated and it was found that in three of the studies, there was a significant correlation between the correction of some parameters of sperm after varicocelectomy, so that in the parameter (Total motility ( $p=0.001)$, the amount of movement before The intervention was 58.77 million and after intervention 64.68 million, while total functional sperm concentration $(p=0.003)$ before intervention was 40.09 and after intervention was 42.06. In this study, the total concentration of sperm Movement before surgery showed varicocelectomy 21.93 and 
after intervention, varicocelectomy was 24.00 which was statistically significant. Varicocelectomy can play a corrective role on the performance of sperm parameters, as some studies have shown that sperm motility can be significantly increased compared to preoperative surgery, while correction of morphology and count was not significant (25). In another study by David I.Chu et al., Varicocelectomy can affect some of the sperm parameters, so that in this study, total motile count was significantly increased and improved, and the count was 2.8 million before Of the surgery reached 18.2 million(26). Shabana et al. showed that varicocelectomy can significantly change and increase the density and progression of sperm motility while the FSH and LH hormones did not change significantly and changes in these hormones were low. On the other hand, the trend of increased testosterone Also effectively increased (27). Other studies have shown that FSH and LH were significantly reduced in patients with hypogonadism, which may be due to an increase in total testosterone levels as a result of improvement in the function of the Leydig cells in the follow-up period. Previous studies did not show a specific effect of varicocelectomy on serum LH even when the mean serum total testosterone improved (19). Leydig cells disorder leads to an increase in FSH and LH in infertile men with varicocele. Fujisawa et al. (2006) stated that patients undergoing varicocelectomy with a decrease in FSH and LH levels (28). In our study, the level of FSH and LH before and after varicocelectomy also changed, however, this difference was not statistically significant, and the level of FSH before and after surgery was $83.8 \mathrm{IU} / \mathrm{L}$ and $72 / 8$, respectively, which was in accordance with other studies. On the other hand, the LH level before and after the surgery was 55/6 IU/L and 7/7 IU/L, respectively, which differs from the previous studies. Chen et al. Showed that the important factors to show the success of the varicocelectomy is the low serum FSH concentration (29). On the contrary, T. Mostafa et al showed that there was no significant difference in FSH levels and fertility rates after varicocelectomy (29). Fuping Li showed that after the surgery of varicocelectomy, the mean serum testosterone level increased. Also, the level of FSH and LH decreased after surgery. This mode is in balance with the negative feedback mechanism of the hypothalamic-pituitory-gland axis (30). ). Kaneko $\mathrm{T}$ et al. Showed that with varicoclotomic, sperm volume increased in teens and adults with two age groups. In patients with improved sperm volume, the level of FSH was significantly reduced. Therefore, one of the results is that serum FSH levels may play a predictive role for post-surgery testicular function (31). Su et al. showed that although varicocelectomy improves serum testosterone, no difference in serum FSH and LH levels and there was no significant relationship between varicocele grade and serum testosterone levels. Also, in terms of semen parameters, sperm motility was significantly increased in comparison with the count of sperm after surgery, which can be explained by the recovery of testosterone synthesis that is necessary for epididymis function (32). In another study, Fujisawa showed that the quality of sperm increased in varicocele patients after varicocelectomy, but no significant difference was found in testosterone levels (33). In a study conducted by Plymate et al in patients with varicocele, a significant increase was seen in serum FSH before surgery, and the quality of semen was impaired, and after serum FSH levels decreased, which could improve in the function of sertoli cells, this is the result of surgery (34). One of the hypotheses related to the effective role of varicocelectomy is the improvement of the testicular environmental temperature after surgery (35). By increasing the testicular scrotum temperature, the concentration of the 5areductase (SRD5A) decreases, which is associated with the effect of converting testosterone to $5 \alpha$-dihydrotestosterone and leading to complications of varicocele in patients. Which is corrected by varicoscultative surgery (36). The function of the Leydig cells is to produce testosterone, which is produced under the control of LH. The role of FSH is the ability to develop testosterone production initially, this process protects by $\mathrm{LH}$, and this function requires which the regular operation of the hypothalamicpituitary-gland axis (37).

In our study, it has been shown that varicocelectomy surgery, as in most previous studies, has a positive effect on testosterone and this effect is significant. On the other hand, for FSH hormone, our study results were consistent with most other results, although this rate was not significant. In the parameters of sperm analysis, our study showed that there was a significant positive effect on sperm motility after the surgery. It should be noted that restrictions in the study process can be effective, limiting the present study, not referring patients after surgery and this limitation prolonged the process of selecting patients and the number of samples for a closer look at the study. It is suggested that this study be done for other parameters of larger sample size to see better results for the effects of this surgery on the infertility process.

\section{Conclusion}

It seems that varicocelectomy have positive effects on parameters such as serum testosterone and FSH levels, as well as sperm count and motility. In this regard, varicocelectomy plays an important role in the treatment of male infertility. For instance, affected men with normal semen parameters may be loss fertility potential in their later life. It seems that varicocelectomy reduces the levels of serum FSH and LH, then improve the performance of the leydig cells and testicles. It can be concluded that varicocelectomy is an effective way to improve fertility and sexual dysfunction in men. 


\section{Compliance with ethical standards}

\section{Acknowledgments}

Authors express their special thanks of gratitude to infertility center for help in this study.

\section{Disclosure of conflict of interest}

The authors declare no competing interests.

\section{Statement of informed consent}

Informed consent was obtained from all individual participants included in the study.

\section{References}

[1] Kantartzi P, Goulis CD, Goulis G, Papadimas I. Male infertility and varicocele: myths and reality. Hippokratia. 2007; 11(3): 99.

[2] Vujkovic M, de Vries JH, Dohle GR, Bonsel GJ, Lindemans J, Macklon NS, et al. Associations between dietary patterns and semen quality in men undergoing IVF/ICSI treatment. Human Reproduction. 2009; 24(6): 1304-12.

[3] Krishna Reddy S. Varicocele and male infertility: Current issues in management-A Review. Med Surg Urol. 2014; 3(2): 137-42.

[4] Sayfan J, Siplovich L, Koltun L, Benyamin N. Varicocele treatment in pubertal boys prevents testicular growth arrest. The Journal of urology. 1997; 157(4): 1456-7.

[5] Said S, Aribarg A, Virutamsen P, Chutivongse S, Koetsawang S, Meherjee P, et al. The influence of varicocele on parameters of fertility in a large group of men presenting to infertility clinics. International Journal of Gynecology \& Obstetrics. 1993; 40(3): 274.

[6] Soheili F, Torabzadeh P, Ramezani M. Effects of Lavandula officinalis aqueous extract on ovaries Balb/c adult female mouse. J Animal Biol. 2017; 9 (4): 47- 56.

[7] Masson P, Brannigan RE. The varicocele. Urologic Clinics. 2014 Feb 1;41(1):129-44.

[8] Gat Y, Gornish M, Heiblum M, Joshua S. Reversal of benign prostate hyperplasia by selective occlusion of impaired venous drainage in the male reproductive system: novel mechanism, new treatment. Andrologia. 2008; 40(5): 273-81.

[9] Naughton CK, Nangia AK, Agarwal A. Varicocele and male infertility: Part II: Pathophysiology of varicoceles in male infertility. Human reproduction update. 2001; 7(5): 473-81.

[10] Damsgaard J, Joensen UN, Carlsen E, Erenpreiss J, Jensen MB, Matulevicius V, et al. Varicocele is associated with impaired semen quality and reproductive hormone levels: a study of 7035 healthy young men from six European countries. European urology. 2016; 70(6): 1019-29.

[11] Tanrikut C, Goldstein M, Rosoff JS, Lee RK, Nelson CJ, Mulhall JP. Varicocele as a risk factor for androgen deficiency and effect of repair. BJU international. 2011; 108(9): 1480-4.

[12] Almahdy AEM, Eldin AAG, Abdullah MM, Abuzaid MI. Varicocele repair outcome with respect to hormonal profile and spermogram pattern. Menoufia Medical Journal. 2014; 27(1): 164.

[13] Binsaleh S, Lo KC. Varicocelectomy: microsurgical inguinal varicocelectomy is the treatment of choice. Canadian Urological Association Journal. 2007; 1(3): 277.

[14] Hsiao W, Rosoff JS, Pale JR, Powell JL, Goldstein M. Varicocelectomy is associated with increases in serum testosterone independent of clinical grade. Urology. 2013; 81(6): 1213-8.

[15] Mehta A, Goldstein M. Microsurgical varicocelectomy: a review. Asian journal of andrology. 2013; 15(1): 56.

[16] Hsiao W, Rosoff JS, Pale JR, Greenwood EA, Goldstein M. Older age is associated with similar improvements in semen parameters and testosterone after subinguinal microsurgical varicocelectomy. The Journal of urology. 2011; 185(2): 620-5. 
[17] Rodriguez Peña M, Alescio L, Russell A, Lourenco da Cunha J, Alzu G, Bardoneschi E. Predictors of improved seminal parameters and fertility after varicocele repair in young adults. Andrologia. 2009; 41(5): $277-81$.

[18] Sathya Srini V, Belur Veerachari S. Does varicocelectomy improve gonadal function in men with hypogonadism and infertility? Analysis of a prospective study. International journal of endocrinology. 2011 Oct;2011.

[19] Ozden C, Ozdal OL, Bulut S, Guzel O, Koyuncu HH, Memis A. Effect of varicocelectomy on serum inhibin B levels in infertile patients with varicocele. Scandinavian journal of urology and nephrology. 2008; 42(5): 441-3.

[20] Zheng YQ, Gao X, Li ZJ, Yu YL, Zhang ZG, Li W. Efficacy of bilateral and left varicocelectomy in infertile men with left clinical and right subclinical varicoceles: a comparative study. Urology. 2009; 73(6): 1236-40.

[21] Reșorlu B, Kara C, Şahin E, Ünsal A. The significance of age on success of surgery for patients with varicocele. International urology and nephrology. 2010; 42(2): 351-6.

[22] Ishikawa T, Fujisawa M. Varicocele ligation on free testosterone levels in infertile men with varicocele. Archives of andrology. 2004; 50(6): 443-8.

[23] Fujisawa M, Hayashi A, Imanishi O, Tanaka H, Okada H, Matsumoto O, et al. The significance of gonadotropinreleasing hormone test for predicting positive effects on Leydig cell function. Fertility and Sterility. 1994; 61: 779-82.

[24] Cakiroglu B, Sinanoglu O, Gozukucuk R. The effect of varicocelectomy on sperm parameters in subfertile men with clinical varicoceles who have asthenozoospermia or teratozoospermia with normal sperm density. International Scholarly Research Notices. 2013.

[25] Chu DI, Zderic SA, Shukla AR, Srinivasan AK, Tasian GE, Weiss DA, et al. Does varicocelectomy improve semen analysis outcomes in adolescents without testicular asymmetry? Journal of pediatric urology. 2017; 13(1): 76. 15 .

[26] Shabana W, Teleb M, Dawod T, Elsayed E, Desoky E, Shahin A, et al. Predictors of improvement in semen parameters after varicocelectomy for male subfertility: A prospective study. Canadian Urological Association Journal. 2015; 9(9-10): E579.

[27] Fujisawa M, Dobashi M, Yamasaki T, Kanzaki M, Okada H, Arakawa S, et al. Significance of serum inhibin B concentration for evaluating improvement in spermatogenesis after varicocelectomy. Human Reproduction. 2001; 16(9): 1945-9.

[28] Chen S-S, Chen L-K. Predictive factors of successful varicocelectomy in infertile patients. Urologia internationalis. 2011; 86(3): 320-4.

[29] Li F, Yue H, Yamaguchi K, Okada K, Matsushita K, Ando M, et al. Effect of surgical repair on testosterone production in infertile men with varicocele: A meta-analysis. International Journal of Urology. 2012; 19(2): 149-54.

[30] Kaneko T, Sasaki S, Yanai Y, Umemoto Y, Kohri K. Effect of microsurgical repair of the varicocele on testicular function in adolescence and adulthood. International Journal of Urology. 2007; 14(12): 1080-3.

[31] Su L-M, Goldstein M, Schlegel PN. The effect of varicocelectomy on serum testosterone levels in infertile men with varicoceles. The Journal of urology. 1995; 154(5): 1752-5.

[32] Fujisawa M, Hayashi A, Imanishi O, Tanaka H, Okada H, Matsumoto O, et al. The significance of gonadotropinreleasing hormone test for predicting fertility after varicocelectomy. Fertility and Sterility. 1994; 61(4): 779-82.

[33] Plymate SR, Paulsen CA, McLachlan R. Relationship of serum inhibin levels to serum follicle stimulating hormone and sperm production in normal men and men with varicoceles. The Journal of Clinical Endocrinology \& Metabolism. 1992; 74(4): 859-64.

[34] Lü YQ, Chen B. Progress in researches on the mechanism of varicocele-induced male infertility. Zhonghua nan ke xue= National Journal of Andrology. 2008 May 1; 14(5):454-8.

[35] Aquila S, Montanaro D, Guido C, Santoro M, Perrotta I, Gervasi S, et al. Human sperm molecular anatomy: the enzyme $5 \alpha$-reductase (SRD5A) is present in the sperm and may be involved in the varicocele-related infertility. Histochemistry and cell biology. 2015; 144(1): 67-76.

[36] Tian D, Huang W, Yan H, Zong H, Zhang Y. Effect of Varicocelectomy on Serum FSH and LH Levels for Patients with Varicocele: a Systematic Review and Meta-analysis. Indian Journal of Surgery. 2018 Jun; 80(3):233-8. 